\title{
edoc
}

Institutional Repository of the University of Basel

University Library

Schoenbeinstrasse 18-20

CH-4056 Basel, Switzerland

http://edoc.unibas.ch/

Year: 2000

\section{Universalist Assumptions and Implications of Comparative Law: should They be Deconstructed?}

\author{
Peters, Anne
}

Posted at edoc, University of Basel

Official URL: http://edoc.unibas.ch/dok/A5264556

Originally published as:

Peters, Anne. (2000) Universalist Assumptions and Implications of Comparative Law : should They be Deconstructed? In: On violence, money, power and culture. Washington D.C., S. 366-369.

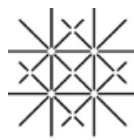




\section{NEW APPROACHES TO COMPARATIVE LAW}

The panel was convened at 2 p.m., Friday, March 26, by its Chair, Marie-Claire Belleau, Université Laval, Quebec, Canada, who introduced the panelists: Larry C. Becker, University of Tulsa College of Law, Tulsa, Oklahoma; Jorge Esquirol, Northeastern University School of Law, Boston, MA; Anne Peters, WaltherSchücking Institute of International Law, Christian Albrechts University, Kiel, Germany; and Mathias Reimann, University of Michigan Law School, Ann Arbor, MI. The comments of one panelist, Anne Peters, are presented here.

\section{UNIVERSALIST ASSUMPTIONS AND IMPLICATIONS OF COMPARATIVE LAW: SHOULD THEY BE DECONSTRUCTED?}

\section{by Anne Peters*}

In this paper, I point out that the traditional comparative method is based on universalist assumptions. I argue against the relativist approach, which recognizes the problem of perspective as a central and determinative element in comparative legal studies, and defend a reconstructed universalist position.

\section{The Comparative Tradition Sprang from a Belief in Progress and Universal Justice}

Historically, European comparative legal studies began with universalist aspirations, in search, so to speak, of the lost unity of natural law. This was in the first half of the 19th century, when the great codifications in Bavaria, Prussia, France and Austria created diverse positive legal rules for specific territories, when the belief in one universal natural (divine) law was declining, and when even the ideal unity of the ius commune Europeaum had been lost.

Comparison of the existing bodies of positive law had primarily idealist, rational and enlightened motives. Comparatists tended to believe that human beings shared a rational nature; they were mostly liberals (in the European sense) who favored modern parliamentary legislation and studied foreign examples in search of material for codification, including projected constitutions.

When, in the 19th century, historicism became the leading paradigm of almost all sciences, legal comparison (including historical comparison) was undertaken in order to construe an inevitable progress of legal evolution. The idea of organic evolution of the law led jurists to search for basic structures of the law-for a "morphology" of the law, of the state, etc. Lawyers both searched for and constructed such evolutionary patterns in order to find the "right law." So, despite the lost belief in natural law, scholars still believed in a universal truth, hidden in historical and national variations, which could be uncovered through legal comparison. Thus, the important German philosopher Wilhelm Dilthey could say: "As the historical school rejected the deduction of general truths in the humanities by means of abstract constructions, the comparative method became the only strategy to reach general truths."

Correspondingly, at the first international conference on comparative law, the famous Paris Congress of 1900, the French comparatist Raymond Saleilles described the object of comparative law as the discovery of concepts and principles common to all "civilized" systems of law, that is, universal concepts and principles that constitute a relatively ideal law ("droit idéal relatif")."

- Dr iur (Freiburg) LL.M (Harvard), lecturer in Law (Kiel).

1 Erich Rothacker, Die vergleichende Methode in den Geisteswissenschaften, 60 ZEITSCHRJFT FOR VERGLEICHENDE RECHTSWISSENSCHAFT 13 (1957), at 15. Translation by author. Emphasis added.

${ }^{2}$ Raymond Saleilles, Conception et objet de la science juridique du droit comparé, in PROCÉs VERBAUX ET DOCUMENTS DU CONGRÉS INTERNATIONAL DE DROIT COMPARE (Paris 1900). 2 vols. (1905-1907), Vol. I, p. 167, at 173. 
Around the 1920 s, as sociology became established as a science, the historicist paradigm gave way to the functional approach, which has dominated comparative legal studies ever since.

The Functional Approach to Comparative Law Is Itself an Offspring and Motor of Universalism

Functional approach means, in contrast to structural approach, that the starting point of comparative analysis is a concrete social problem. In other words, the starting point is not the law, the structure of legal institutions, but the facts.

To what extent does this functional approach imply, in particular, objectivity and universality of the law? Because it rests on the assumption that "the legal system of every society faces essentially the same problems, and solves these problems by quite different means though very often with similar results." ${ }^{3}$ The underlying theory is that law is an answer to the needs of society and an instrument of social change.

This view of the law almost inevitably leads to a theory of natural convergence of legal systems as a consequence of regional integration and even globalization and the resulting competition between legal orders. As lifestyles in different countries converge, as a result of the leveling of economic and moral standards and economic and political integration, the legal rules that react to social needs must naturally converge as well, so the theory runs. National characteristics of legal rules will gradually disappear with the emergence of a global society. The question is, however, whether natural convergence is merely a euphemism for North American, and to a lesser extent, European legal imperialism.

\section{How Should the Comparatist Evaluate Legal Rules?}

One of the most interesting questions concerning the comparative method is: Should a comparative study conclude with an evaluation of the studied concepts? Or should we rather abstain from evaluation? Can we abstain from evaluation?

Traditional positions imply, first, that evaluation is a conscious act separable from the mere "neutral" description of the law; second, that evaluation is useful, because it is "objective."

The relativist position calls these assumptions into question. It holds that there is no external, neutral standpoint from which to evaluate legal solutions. Even if we explicitly abstain from evaluating, our whole investigation and presentation will be full of (unconscious) judgments. We are unavoidably biased, so that any attempt at a neutral description is an illusion, merely covering up our own Eurocentric (or otherwise Western) views. This is because, according to a more logical version of relativism, there are no secure basic truths or axioms. All legal solutions are relative to a specific culture or society. In a more linguistic version, relativism asserts that there is no real communication among people arguing on the basis of incommensurable frameworks. Therefore, in such a discussion, no rational reasons can be given for the preference of one theory over the other. Therefore, such thing as a "better" legal solution does not exist.

If this is true, then comparative studies have a limited value, because they are only a projection-an outgrowth of our specific worldview, of our theoretical and moral framework.

I do not think that this is necessarily the case, because the basis for this claim, relativism, understood as the denial of the possibility of objectivity and universal truth, is flawed.

Various arguments can be made against relativism. A more formal argument is that relativism is self-defeating, because the more radical it is, the more it weakens its own claim to validity. Extreme relativism is a contradiction in itself to the extent that it holds the relativist position as true. Talking about frameworks and about their incommensurability presupposes that the speaker occupies a position beyond the frameworks. Otherwise, the speaker could not make that statement. Another more formal argument is that relativism is immune to critique, because it can attribute every objection or critique to another worldview or framework.

\footnotetext{
${ }^{3}$ KONRAD ZWIGERT \& HEIN KOTZ, INTRODUCTION TO COMPARATIVE LAW-THE FRAMEWORK, p. 34 (TonY Weir, trans. Clarendon Press, Oxford 3d ed. 1998) (1969). Emphasis added.
} 
A practical argument against relativism is that it is a typically academic theory. In everyday legal life, it is not practicable, because here commensurability of worldviews is needed. Critique must stop at a certain point if one is to make definite judgments. Radical relativism is inherently incapable of refuting totalitarian and inhuman ideologies. Human rights activists could not pursue their goals on the basis of such a theory.

An argument directed against the more logical version of relativism is formulated by Karl Popper. According to Popper, the denial of rationality is based on the false assumption that every rational discussion must start from some premise, principle or axiom, which must be accepted dogmatically if we wish to avoid an infinite regress. However, critical discussions are possible without seeking to prove, justify or establish a theory. One objective of discussions should be to test the theory under consideration by finding out whether its consequences are either acceptable or undesirable. ${ }^{4}$

Contrary to the relativist claim of the impossibility of communication across frameworks, academic business shows that there is such communication. Denying the possibility of communication is probably a good excuse for shielding oneself from external critique.

A different question is whether we are psychologically capable of transcending our framework, even if, as a matter of logic and language, such transcendence is feasible. One cannot give an all-or-nothing answer to this question. Different individuals are to different degrees willing and able to distance themselves from their culture and socialization. Escaping from one's framework will be facilitated through discussion with others, particular through cross-cultural discussion.

From these arguments follows my own position on the question of evaluation: An evaluation of the legal rules and institutions under study is desirable. It makes sense because of the possibility of critique within the scientific community. Others may evaluate the research result differently than I do, and may come to quite different conclusions. My value judgment can be disproved (or confirmed) by other researchers, especially by those who have been socialized in a different moral or legal framework. They can assess my data, my arguments and my conclusions.

\section{Conclusion: Comparative Studies Help Create Critical Distance}

The critical deconstruction of the comparative approach has the merit of reminding us of highly self-conscious and self-critical methodological guidance.

The approach suggested here is "critical" to the extent that it strives to unmask the cultural bias and prejudices on the part of the comparatist that may engender an ethnocentric interpretation of facts and may result in formalist ordering and misleading labeling.

Furthermore, my approach is a comprehensive and interdisciplinary one, which looks not only at rules but at legal cultures, traditions, ideologies, identities and entire legal discourses. This insight is not new. Traditional functionalists have called for interdisciplinarity, though perhaps in different terms. With regard to the dangers of a false universalism, interdisciplinarity and comprehensiveness appear, however, in a new light. They direct our attention to the moral and political, possibly dysfunctional underpinnings of rules in a historical and sociological perspective. So, interdisciplinarity and comprehensiveness are a conditio sine qua non for avoiding erroneous assumptions concerning ostensibly "identical" societal problems and erroneous, decontextualized evaluations of legal solutions.

However, my approach is universalist to the extent that it includes a belief in the existence of some universal legal principles. These do not constitute a preexisting universal "right" law, but, rather, principles that have evolved in a process of trial and error.

\footnotetext{
${ }^{4}$ KARL R. POPPER, THE MYTH OF THE FRAMEWORK, in Id., THE MYTH OF THE FRAMEWORK: IN DEFENCE OF SCIENCE AND RATIONALITY p. 33 at 60-61 (1994).
} 
So, without falling into a unificatory enthusiasm, I submit that comparative studies may clear the way for cautious adoption and adaptation of foreign solutions for purposes of experimenting with them.

Evaluation of (foreign or domestic) legal solutions is possible and desirable, because the comparatist is capable of escaping his or her framework, and because all judgments are subject to critique. Thus, I primarily view comparative law as an operator of critique: Comparative legal studies help to create a critical intellectual distance from one's legal system. 